\title{
Chelating Polymer Bearing 2-(2-Diazolylazo)phenol Moiety for Adsorbent of Heavy Metal Ions
}

\author{
Yasuo ONARI \\ Mie Industrial Research Institute, Takajayakomori-cho, Tsu 514, Japan
}

\begin{abstract}
Chelating polymer bearing 2-(2-diazolylazo)phenol moiety was synthesized and its metal adsorption properties for 6 divalent heavy metal ions $\left(\mathrm{M}^{2+}\right): \mathrm{Co}^{2+}, \mathrm{Ni}^{2+}, \mathrm{Cu}^{2+}, \mathrm{Zn}^{2+}, \mathrm{Cd}^{2+}$ and $\mathrm{Pb}^{2+}$ were investigated. The polymer changed color from orange yellow to blue or to red violet with its chelation to $\mathrm{Cu}^{2+}$ or to $\mathrm{Ni}^{2+}$, respectively. The maximum capacity of the polymer for $\mathrm{Cu}^{2+}$ was found to be $1.35 \mathrm{meq} / \mathrm{g}$ in $\mathrm{pH} 5.71$ solution. The degrees of saturation of the capacity of the polymer after shaking for $30 \mathrm{~min}$ were $\mathbf{7 1 . 3}$ and $\mathbf{8 3 . 6 \%}$ for the adsorptions of $\mathrm{Zn}^{2+}$ and $\mathrm{Cu}^{2+}$, respectively. The capacity of the polymer for $\mathrm{M}^{2+}$ hardly varied with the presence of alkali or alkaline earth metal ions. The elimination of metals from the polymer- $\mathrm{M}^{2+}$ chelates was achieved with $4 \mathrm{~mol} / 1 \mathrm{HCl}$ or $4 \mathrm{~mol} / 1 \mathrm{H}_{2} \mathrm{SO}_{4}$ solution.
\end{abstract}

Keywords Chelating polymer, 2-(2-diazolylazo)phenol moiety, metal adsorption ability, heavy metal ion

In previous reports ${ }^{1,2}$, the chelating polymers bearing 2-(3-triazolylazo)phenol or 4-(3-triazolylazo)phenol moiety as a functional group were synthesized and the metal adsorption abilities of these polymers for 6 divalent heavy metal ions $\left(\mathrm{M}^{2+}\right)$ : $\mathrm{Co}^{2+}, \mathrm{Ni}^{2+}, \mathrm{Cu}^{2+}, \mathrm{Zn}^{2+}, \mathrm{Cd}^{2+}$ and $\mathrm{Pb}^{2+}$ were investigated. The color changes of the polymer bearing 2-(3-triazolylazo)phenol moiety in the formation of the polymer- $\mathrm{M}^{2+}$ chelate were remarkable, but the color of the polymer containing 4-(3-triazolylazo)phenol group did not appear to change remarkably with the $\mathrm{M}^{2+}$ chelatè formation, except for its chelation with $\mathrm{Cu}^{2+}$. The magnitude of decrease in the capacity of the polymer containing 4-(3-triazolylazo)phenol group for $\mathrm{M}^{2+}$ with lowering of $\mathrm{pH}$ was larger than that in the capacity of the polymer bearing 2-(3-triazolylazo)phenol moiety. From these experimental results, in the chelate formation of the polymer bearing triazolylazophenol moiety, which has nitrogen as the only hetero atom of azole ring (5 membered heteroaromatic ring), with transition metal ions, the effect of the donor oxygen atom of its phenol group was known. However, the function of the donor nitrogen atom of its azole ring on the polymer- $\mathrm{M}^{2+}$ chelate formation is still not elucidated. In order to reveal the metal adsorption ability of the polymer bearing azole ring as a component of its orthohydroxyazo-heteroaromatic group, the effect of variation in the number of nitrogen atoms of the azole ring, therefore, is an interesting subject for investigation.

In the present work, the polymer bearing 2-(2diazolylazo)phenol moiety -was newly prepared, and its metal adsorption properties for $\mathrm{M}^{2+}$ were investigated. The purpose of this paper is to examine the effect of the decrease of the number of nitrogen atoms of the azole ring on the metal adsorption ability of the chelating polymer bearing ortho-hydroxyazo-heteroaromatic moiety as a functional group, and to investigate the application of this polymer for removal of heavy metals from plating process solutions. Some monomeric diazolylazophenol derivatives and their chelate forming abilities with transition metal ions have already been reported ${ }^{3-7}$, but little is known about the polymer bearing diazolylazophenol moiety.

\section{Experimental}

\section{Measurement}

Proton nuclear magnetic resonance (NMR) spectra were taken on a Hitachi $60 \mathrm{MHz}$ R-24B high resolution spectrometer in acetone- $d_{6}$ at $35^{\circ} \mathrm{C}$ by employing TMS as an internal standard. Infrared absorption spectra were measured on a Nihon Bunko IRA-2 spectrometer. Ultraviolet absorption spectra were obtained using a Hitachi 323 spectrophotometer in methanol at room temperature. Elemental analysis was performed on a Yanaco MT-3 CHN Corder. A Hitachi 308 atomic absorption spectrophotometer and EDTA titration were employed for the determination of metal concentrations.

\section{Reagents}

Metal ion solutions were prepared by dissolving the reagent grade metal nitrate in distilled water. Acetate buffer solutions $\left(\mathrm{CH}_{3} \mathrm{CO}_{2} \mathrm{H} / \mathrm{CH}_{3} \mathrm{CO}_{2} \mathrm{Na}, 0.2 \mathrm{M}\right)$ were used to adjust $\mathrm{pH}$ values.

\section{Preparation of the chelating polymer}

$p$-Vinylphenol was prepared by employing $p$-hydroxybenzaldehyde as a starting material in nearly the same way 
as the method reported previously. ${ }^{1}$ The properties of the synthesized $p$-vinylphenol were presented in the previous report. ${ }^{1}$

The chelating polymer was prepared by the conventional diazotizated coupling reaction of $4.4 \mathrm{~g}$ of 2-amino1,3-diazole with $2.0 \mathrm{~g}$ of $p$-vinylphenol polymer. The obtained chelating polymer was used for experiment as a wet polymer of $79.98 \%$ moisture content:" yield $2.1 \mathrm{~g}$

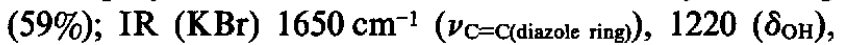

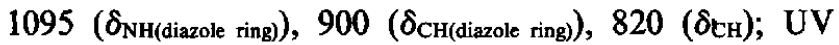
(methanol) $\lambda_{\max } 280 \mathrm{~nm}, 370$; Anal. Calcd. for $\left(\mathrm{C}_{11} \mathrm{H}_{10} \mathrm{~N}_{4} \mathrm{O}\right)_{n}: \mathrm{C}, 61.67 ; \mathrm{H}, 4.71 ; \mathrm{N}, 26.15 \%$. Found for the chelating polymer: $\mathrm{C}, 69.89 ; \mathrm{H}, 6.15 ; \mathrm{N}, 5.46 \%$. This indicates an approximate composition of $12.9 \mathrm{~mol} \%$ diazolylazo-vinylphenol. The polymer was soluble in organic solvents such as methanol and $N, N$-dimethylformamide.

\section{Elimination of adsorbed $\mathrm{M}^{2+}$}

The elimination of $\mathrm{M}^{2+}$ from its polymer chelate was carried out with a mineral acid solution in the following manner. The wet polymer, $1 \mathrm{~g}$, was equilibrated with $50 \mathrm{ml}$ of the buffered solution of $\mathrm{M}^{2+}\left(\mathrm{ca} \cdot 10^{-2} \mathrm{~mol} / \mathrm{l}\right)$, and its $\mathrm{M}^{2+}$ chelate was obtained from the solution by centrifugation. The chelate was washed with $10 \mathrm{ml}$ distilled water, followed by treatment with a mineral acid solution.

\section{Removal of heavy metals from plating process solutions}

The applicability of the chelating polymer for removal of heavy metal ions from plating process solutions was examined. A mixture of $50 \mathrm{ml}$ of the acetate buffer solution containing the metal and $1 \mathrm{~g}$ of wet polymer was equilibrated for $30 \mathrm{~min}$, after which time the remaining concentration of metal was determined by using atomic absorption spectrometry.

\section{Results and Discussion}

\section{Metal adsorption ability of the chelating polymer}

In analogy with the case of monomeric diazolylazophenol derivatives ${ }^{3-7}$, this chelating polymer changed color with its chelation to heavy metal ions; such color changes were reversible with chelate deformation. The colors of this chelating polymer in chelate formation of the polymer- $\mathrm{M}^{2+}$ are shown in Table 1 .

The effect of $\mathrm{pH}$ on the capacity of the chelating polymer for $\mathrm{M}^{2+}$ is shown in Fig. 1. A solution $(50 \mathrm{ml})$ containing metal ions (ca. $\left.10^{-2} \mathrm{~mol} / \mathrm{l}\right)$, the $\mathrm{pH}$ of which was controlled with $0.2 \mathrm{M}$ acetate buffer, and $1 \mathrm{~g}$ of wet polymer were placed in a $300-\mathrm{ml}$ flask. The mixture was shaken and equilibrated for $6 \mathrm{~h}$ at $23^{\circ} \mathrm{C}$, after which time the chelate was excluded immediately by centrifugation. The metal ion concentration of the supernatant was determined by EDTA titration with Xylenol Orange (XO), 1-(2-pyridylazo)-2-naphthol (PAN) or mixture of $\mathrm{Cu}-E D T A$ and PAN (Cu-PAN) as a metal indicator. If 2-(2-diazolylazo)phenol moiety of the polymer forms a
Table 1 Color and absorption maxima of polymer- $\mathrm{M}^{2+}$ chelates

\begin{tabular}{ccl}
\hline Metal ion & $\lambda_{\max } / \mathrm{nm}$ & \multicolumn{1}{c}{ Color } \\
\hline- & 450 & orange yellow \\
$\mathrm{Co}^{2+}$ & 620 & orange red \\
$\mathrm{Ni}^{2+}$ & 600 & red violet \\
$\mathrm{Cu}^{2+}$ & 650 & blue \\
$\mathrm{Zn}^{2+}$ & 625 & red orange \\
$\mathrm{Cd}^{2+}$ & 595 & orange \\
$\mathrm{Pb}^{2+}$ & 640 & orange \\
\hline
\end{tabular}

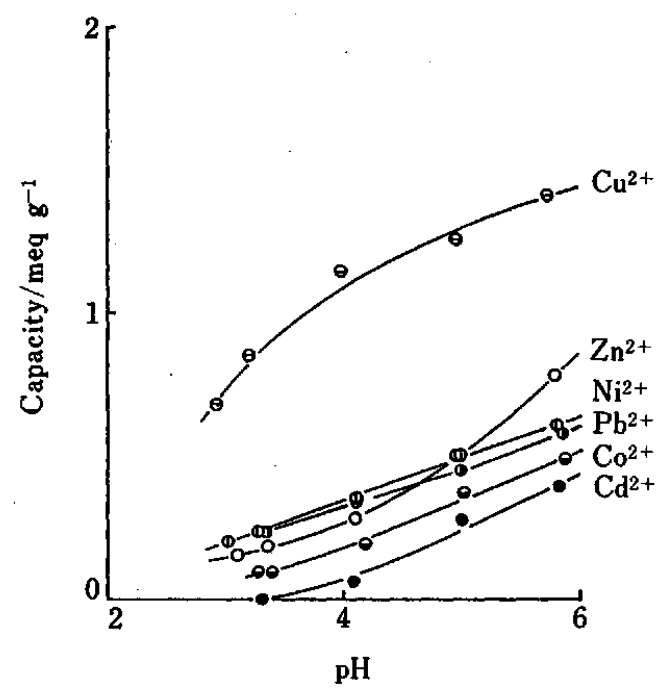

Fig. 1 Effects of $\mathrm{pH}$ on the capacities of the chelating polymer for the heavy metal ions at $23^{\circ} \mathrm{C}$. Shaking time, $6 \mathrm{~h}$; buffer solution, $\mathrm{CH}_{3} \mathrm{CO}_{2} \mathrm{H} / \mathrm{CH}_{3} \mathrm{CO}_{2} \mathrm{Na}, 0.2 \mathrm{M}$.

1 : 1 chelate with $\mathrm{M}^{2+}$, the maximum capacity for $\mathrm{M}^{2+}$ was expected to be $1.95 \mathrm{meq} / \mathrm{g}$ according to elemental analysis. The observed maximum capacity of the polymer for $\mathrm{M}^{2+}$ was $1.35 \mathrm{meq} / \mathrm{g}$ for adsorption of $\mathrm{Cu}^{2+}$ at pH 5.71. The achieved maximum capacity was about $69.2 \%$ of its expected value. Of the metals, $\mathrm{Cu}^{2+}$ was most strongly adsorbed by the polymer in the $\mathrm{pH}$ region of 3.0-5.7. The capacity of this chelating polymer for $\mathrm{Cu}^{2+}$ was shown to be twice, or a little more, that for the other metal ions. The result indicated the formation of a $1: 1$ chelate (metal: diazolylazophenol moiety of the polymer), but the other metal ions probably formed $1: 2$ chelates with it.

Typical isotherm adsorption curves measured for the chelating polymer with $\mathrm{M}^{2+}$ are shown in Fig. 2. The 1/ $n$ values of the Freundlich equation $(\log q=\log k+(1 /$ $n) \log C$ ) evaluated for $\mathrm{Cu}^{2+}$ and $\mathrm{Zn}^{2+}$ adsorptions by the polymer were 0.09 and 0.34 , respectively. For metal adsorbing agents, $1 / n$ value obtained from the Freundlich equation should be in the range of about $0.1-0.5$ in order for the agent to be applied to practical use. These metals were shown to be effectively adsorbed by the 


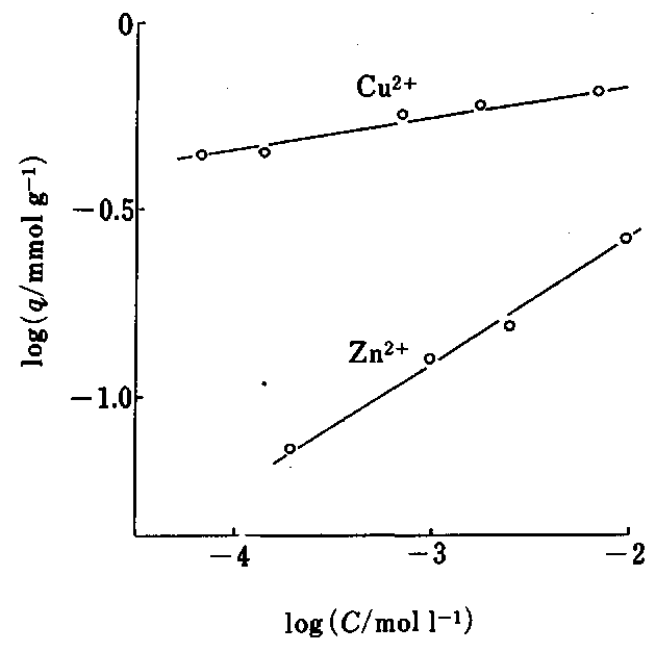

Fig. 2 Isotherm adsorption curves for the adsorptions of $\mathrm{Cu}^{2+}$ and $\mathrm{Zn}^{2+}$ by the chelating polymer at $23^{\circ} \mathrm{C}$. Shaking time, $6 \mathrm{~h}$; pH, $4.93\left(\mathrm{Cu}^{2+}\right)$ and $5.0\left(\mathrm{Zn}^{2+}\right)$.

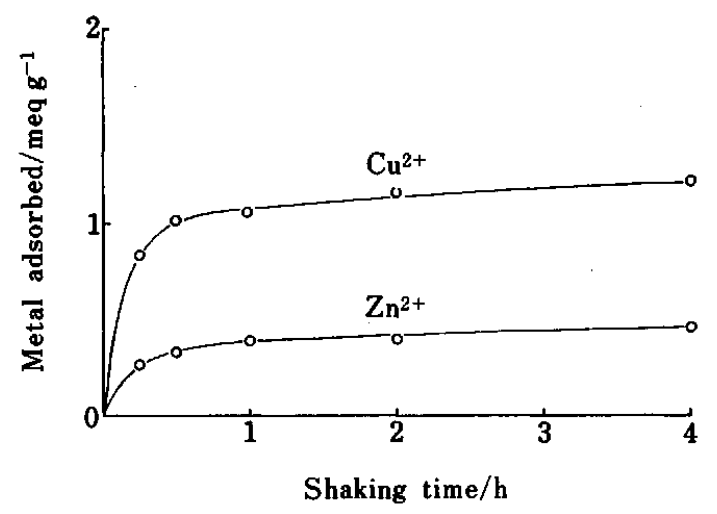

Fig. 3 Effects of shaking time on the adsorptions of $\mathrm{Cu}^{2+}$ and $\mathrm{Zn}^{2+}$ by the chelating polymer at $23^{\circ} \mathrm{C}$. $\mathrm{pH}, 4.97\left(\mathrm{Cu}^{2+}\right)$ and $4.99\left(\mathrm{Zn}^{2+}\right)$.

polymer.

The effect of shaking time on the capacity of the chelating polymer for $\mathrm{M}^{2+}$ was examined at $23^{\circ} \mathrm{C}$ (Fig. 3). The time needed for perfect saturation of the capacity of the polymer for $\mathrm{M}^{2+}$ was about $4 \mathrm{~h}$. The degrees of saturation after shaking for $30 \mathrm{~min}$ were 71.3 and $83.6 \%$ for the adsorption of $\mathrm{Zn}^{2+}$ and $\mathrm{Cu}^{2+}$, respectively. Compared with the equilibration rate of the chelating polymer bearing 2-(3-triazolylazo)phenol moiety as a functional group ${ }^{1}$, the rate of the polymer bearing $2-(2-$ diazolylazo)phenol moiety was slow.

The effect of the presence of alkali or alkaline earth metal ions on the capacity of the chelating polymer for $\mathrm{M}^{2+}$ was examined. The relationship between the capacity of the polymer for $\mathrm{Cu}^{2+}$ and the amount of the coexisting $\mathrm{KNO}_{3}$ (or $\mathrm{CaCl}_{2}$ ) is shown in Fig. 4. The capacity of the polymer for the heavy metal ion varied little with the presence of these ions. Neither the coexistence of $\mathrm{NaCl}$ nor of $\mathrm{Mg}\left(\mathrm{NO}_{3}\right)_{2}$ affected the

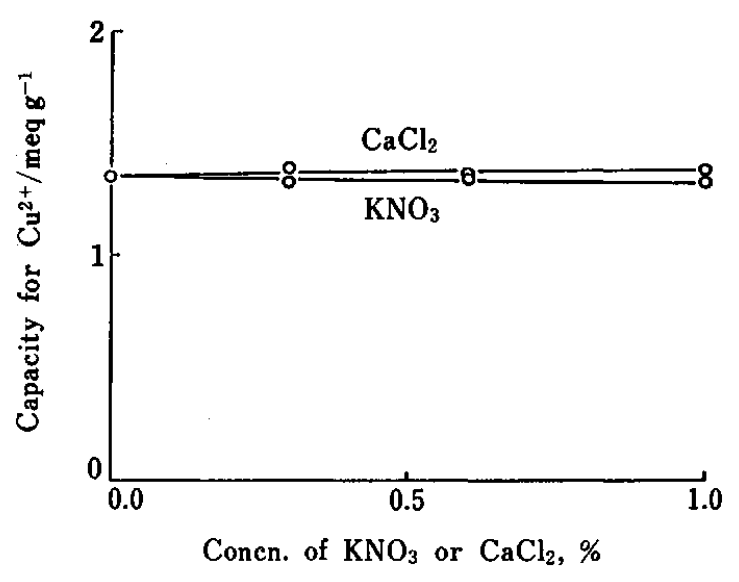

Fig. 4 Effect of alkali or alkaline earth metal ion on the chelation of the polymer to $\mathrm{Cu}^{2+}$ at $23^{\circ} \mathrm{C}$. Shaking time, $6 \mathrm{~h}$; $\mathrm{pH}, 4.95$.

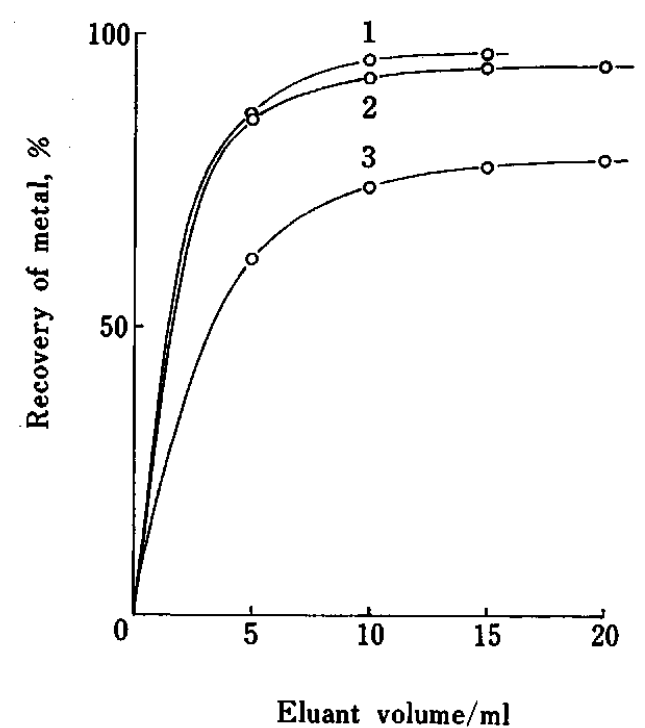

Fig. 5 Elimination of metal ions from the polymer-M $\mathrm{M}^{2+}$ chelates by mineral acids solutions at $23^{\circ} \mathrm{C}$. Initial amount of the adsorbed $\mathrm{M}^{2+}$ : $\mathrm{Cu}^{2+}, 1.47 \times 10^{-4} \mathrm{~mol} ; \mathrm{Zn}^{2+}, 0.80 \times 10^{-4}$ mol. 1: $\mathrm{Zn}^{2+}$ chelate-1 mol/1 HCl; $2: \mathrm{Cu}^{2+}$ chelate- $4 \mathrm{~mol} / 1$ $\mathrm{H}_{2} \mathrm{SO}_{4} ; 3: \mathrm{Cu}^{2+}$ chelate-1 mol/1 HCl .

capacity.

\section{Elimination of metal ions from polymer- $M^{2+}$ chelates}

The results are shown in Fig. 5. Similarly to the cases of the polymers bearing triazolylazophenol moiety as functional group ${ }^{1,2}, \mathrm{Zn}^{2+}$ wąs quantitatively eluted from the polymer with $1 \mathrm{~mol} / 1 \mathrm{HCl}$ solution, but $4 \mathrm{~mol} / 1$ $\mathrm{H}_{2} \mathrm{SO}_{4}$ solution was required to eliminate $\mathrm{Cu}^{2+}$. A $90 \%$ removal of $\mathrm{Cu}^{2+}$ and of the other metal ions from the polymer- $\mathrm{M}^{2+}$ chelates, respectively, was achieved with $4 \mathrm{~mol} / 1 \mathrm{H}_{2} \mathrm{SO}_{4}$ solution ( $c a .197$ times equivalent of adsorbed $\mathrm{Cu}^{2+}$ ) and $1 \mathrm{~mol} / 1 \mathrm{HCl}$ solution (ca. 38 times that of adsorbed $\mathrm{M}^{2+}$ ). 
Table 2 Adsorption of heavy metal ions in plating-process solutions by the chelating polymer at $23^{\circ} \mathrm{C}$

\begin{tabular}{cllccc}
\hline Sample & $\mathrm{pH}$ & Metal ion & $\begin{array}{c}\text { Initial concn. } \\
\text { of metal } / \mathrm{mol} \mathrm{l}^{-1}\end{array}$ & $\begin{array}{c}\text { Remaining conc. } \\
\text { of metal } / \mathrm{mol} \mathrm{l}^{-1}\end{array}$ & Capacity $/ \mathrm{meq}^{-1}$ \\
\hline $\mathrm{A}$ & 3.90 & $\mathrm{Ni}^{2+}$ & $9.09 \times 10^{-3}$ & $8.75 \times 10^{-3}$ & 0.17 \\
& $5.98^{\mathrm{a}}$ & $\mathrm{Ni}^{2+}$ & $9.09 \times 10^{-3}$ & $8.15 \times 10^{-3}$ & 0.47 \\
$\mathrm{~B}$ & 7.43 & $\mathrm{Cu}^{2+}$ & $9.07 \times 10^{-3}$ & $8.25 \times 10^{-3}$ & 0.41 \\
& $6.45^{\mathrm{a}}$ & $\mathrm{Cu}^{2+}$ & $9.07 \times 10^{-3}$ & $8.05 \times 10^{-3}$ & 0.51 \\
$\mathrm{C}$ & $5.80^{\mathrm{a}}$ & $\mathrm{Cu}^{2+}$ & $4.46 \times 10^{-3}$ & $2.90 \times 10^{-3}$ & 0.78 \\
& & $\mathrm{Zn}^{2+}$ & $2.18 \times 10^{-3}$ & $2.18 \times 10^{-3}$ & 0 \\
\hline
\end{tabular}

a. pH was controlled with $0.2 \mathrm{M}$ acetate buffer.

Removal of heavy metal ions from platïn process solutions

The chelating polymer was also applied to the adsorption of heavy metal ions from plating process solutions (Table 2). In the electrolytic copper-plating process solutions, the capacity of the polymer for $\mathrm{Cu}^{2+}$ in the buffered solution ( $\mathrm{pH} \mathrm{6.45)}$ was larger than that in the initial solution ( $\mathrm{pH} 7.43$ ). This may be due to the presence of $\mathrm{NH}_{3}$ in the plating process solution, as was shown in the previous reports. ${ }^{1-2}$ In the case of the solution of the chemical polishing process of copper-zinc alloy, as was expected from the Irving-Williams order, the selective adsorption of $\mathrm{Cu}^{2+}$ was achieved in the buffered solution (pH 5.80).

\section{References}

1. Y. Onari, J. Appl. Polym. Sci, 31, 1663 (1986).

2. Y. Onari, J. Appl. Polym. Sci., 35, 1695 (1988).

3. H. Tanaka and O. Yamauchi, Chem. Pharm. Bull., 12, 1268 (1964).

4. O. Yamauchi, H. Tanaka and T. Uno, Talanta, 15, 177 (1968).

5. O. Yamauchi, H. Tanaka and T. Uno, Talanta, 15, 459 (1968).

6. H. Wada and G. Nakagawa, Bunseki Kagaku, 24, 239 (1975).

7. U. Folli, D. Larossi and P. Vivarelli, J. Soc. Dyers Colour., 96, 414 (1980). 